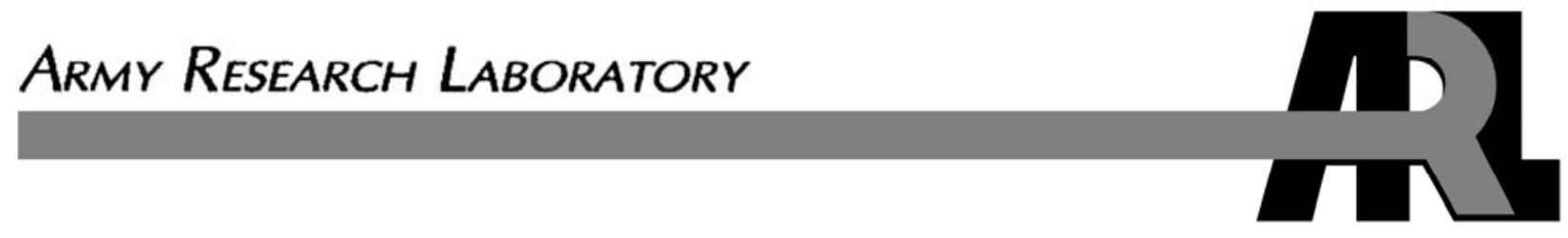

\title{
Using a Cognitive Architecture to Solve Simultaneous Localization and Mapping (SLAM) Problems
}

\author{
by Troy D. Kelley
}

ARL-MR-0639

May 2006

Approved for public release; distribution is unlimited. 


\section{NOTICES}

\section{Disclaimers}

The findings in this report are not to be construed as an official Department of the Army position unless so designated by other authorized documents.

Citation of manufacturer's or trade names does not constitute an official endorsement or approval of the use thereof.

DESTRUCTION NOTICE—Destroy this report when it is no longer needed. Do not return it to the originator. 


\title{
Army Research Laboratory
}

Aberdeen Proving Ground, MD 21005-5425

\section{Using a Cognitive Architecture to Solve Simultaneous Localization and Mapping (SLAM) Problems}

\author{
Troy D. Kelley \\ Human Research and Engineering Directorate, ARL
}


Public reporting burden for this collection of information is estimated to average 1 hour per response, including the time for reviewing instructions, searching existing data sources, gathering and maintaining the data needed, and completing and reviewing the collection information. Send comments regarding this burden estimate or any other aspect of this collection of information, including sugestions for reducing the burden,

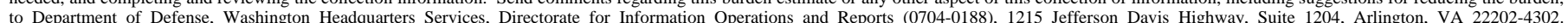

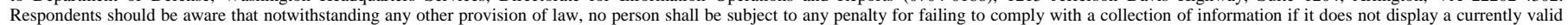
OMB control number.

PLEASE DO NOT RETURN YOUR FORM TO THE ABOVE ADDRESS.

\begin{tabular}{|c|c|c|}
\hline $\begin{array}{l}\text { 1. REPORT DATE (DD-MM-YYYY) } \\
\text { May } 2006\end{array}$ & $\begin{array}{l}\text { 2. REPORT TYPE } \\
\text { Final }\end{array}$ & $\begin{array}{l}\text { 3. DATES COVERED (From - To) } \\
\text { May } 2005\end{array}$ \\
\hline \multirow{4}{*}{\multicolumn{2}{|c|}{$\begin{array}{l}\text { 4. TITLE AND SUBTITLE } \\
\text { Using a Cognitive Architecture to Solve Simultaneous Localization and } \\
\text { Mapping (SLAM) Problems }\end{array}$}} & 5a. CONTRACT NUMBER \\
\hline & & \\
\hline & & 5b. GRANT NUMBER \\
\hline & & 5c. PROGRAM ELEMENT NUMBER \\
\hline \multicolumn{2}{|l|}{ 6. AUTHOR(S) } & $\begin{array}{l}\text { 5d. PROJECT NUMBER } \\
\text { 62716AH70 }\end{array}$ \\
\hline \multirow{2}{*}{\multicolumn{2}{|c|}{ Troy D. Kelley (ARL) }} & 5e. TASK NUMBER \\
\hline & & 5f. WORK UNIT NUMBER \\
\hline \multicolumn{2}{|c|}{$\begin{array}{l}\text { 7. PERFORMING ORGANIZATION NAME(S) AND ADDRESS(ES) } \\
\text { U.S. Army Research Laboratory } \\
\text { Human Research and Engineering Directorate } \\
\text { Aberdeen Proving Ground, MD 21005-5425 }\end{array}$} & $\begin{array}{l}\text { 8. PERFORMING ORGANIZATION } \\
\text { REPORT NUMBER } \\
\text { ARL-MR-0639 }\end{array}$ \\
\hline \multirow{2}{*}{\multicolumn{2}{|c|}{ 9. SPONSORING/MONITORING AGENCY NAME(S) AND ADDRESS(ES) }} & 10. SPONSOR/MONITOR'S ACRONYM(S) \\
\hline & & $\begin{array}{l}\text { 11. SPONSOR/MONITOR'S REPORT } \\
\text { NUMBER(S) }\end{array}$ \\
\hline
\end{tabular}

12. DISTRIBUTION/AVAILABILITY STATEMENT

Approved for public release; distribution is unlimited.

13. SUPPLEMENTARY NOTES

\section{ABSTRACT}

The cognitive production system architecture, the Atomic Components of Thought-Rational (ACT-R), was applied to the problem of simultaneous localization and mapping (SLAM). The map space was represented as a pseudo-topological map of salient features, which was then evaluated with a production system architecture (ACT-R). Results showed that after the robot was placed in five unique locations, it was able to recognize them as spaces that it had previously visited. Results also showed that intrinsic error associated with robotic sensor readings was overcome with the use of the simulated human memory activation equations of ACT-R.

15. SUBJECT TERMS

cognitive modeling; robotics; SLAM

\begin{tabular}{|c|c|c|c|c|c|}
\hline \multicolumn{3}{|c|}{ 16. SECURITY CLASSIFICATION OF: } & \multirow{2}{*}{$\begin{array}{l}\text { 17. LIMITATION } \\
\text { OF ABSTRACT } \\
\text { SAR }\end{array}$} & \multirow{2}{*}{$\begin{array}{c}\text { 18. NUMBER } \\
\text { OF PAGES } \\
18\end{array}$} & \multirow{2}{*}{$\begin{array}{l}\text { 19a. NAME OF RESPONSIBLE PERSON } \\
\text { TrOy D. Kelley } \\
\text { 19b. TELEPHONE NUMBER (Include area code) } \\
\text { 410-278-5859 }\end{array}$} \\
\hline $\begin{array}{l}\text { a. REPORT } \\
\text { Unclassified }\end{array}$ & $\begin{array}{l}\text { b. ABSTRACT } \\
\text { Unclassified }\end{array}$ & $\begin{array}{l}\text { c. THIS PAGE } \\
\text { Unclassified }\end{array}$ & & & \\
\hline
\end{tabular}




\section{Contents}

List of Figures $\quad$ iv

List of Tables $\quad$ iv

$\begin{array}{lr}\text { 1. Introduction } & 1\end{array}$

2. Method 2

3. Procedure $\quad 2$

3.1 Background 2

3.2 Knowledge Development 3

3.3 Localization 5

$\begin{array}{lll}3.4 & \text { Summary } & 8\end{array}$

$\begin{array}{lr}\text { 4. Conclusions } & 9\end{array}$

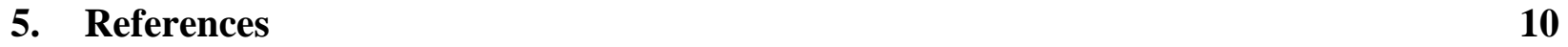

$\begin{array}{ll}\text { Distribution List } & 11\end{array}$ 


\section{List of Figures}

Figure 1. Activation values decreasing, increasing and returning to zero...................................... 3

Figure 2. Robotic visual angle in degrees and activation values associated with line objects...... 4

Figure 3. Approximate layout of room and five locations the robot was to learn......................... 6

Figure 4. Line group activation values for three groups of lines.................................................. 8

\section{List of Tables}

Table 1. Five scene locations, in rule based format, first scan. ..................................................... 6

Table 2. Five scene locations, rule based format, second scan................................................... 7

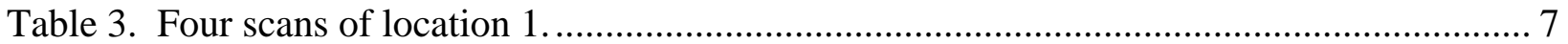




\section{Introduction}

This report describes the ongoing development of a robotic control architecture called the Symbolic and Subsymbolic Robotic Intelligence Control System (SS-RICS). The system was inspired by computational cognitive architectures from the discipline of cognitive psychology. The idea is that by applying cognitive psychological principles to robotics, perhaps some of the more difficult problems of localization and mapping might be solved.

Cognitive psychologists have made enormous progress in understanding the human mind over the past two decades; moreover, psychologists have had great success in implementing human cognitive theories computationally (1). The implementation of human cognitive function in a computational format has allowed cognitive theories to become more bounded, rigorous, and testable. This development has allowed for cognitive theories to be tested on computer systems, including robotic systems. The goal of this research is to show how cognitive psychological principles can be applied to simultaneous localization and mapping (SLAM) problems.

Humans have an inexact sense of space and spatial relationships. Understanding how humans develop a spatial knowledge of the world may help to develop robotic platforms that have an efficient working spatial knowledge of the world. Robots, like humans, have sensors that render an inexact representation of the world. Thus, any representational mechanism of spatial knowledge implemented on a robot must support incomplete and error-prone data, or what one psychological researcher calls "states of partial knowledge" (2). The conclusion from many psychologists is that humans use minimal spatial representations and try to maximize the benefit from such a paucity of spatial representation.

One classic example of using minimal representations of spatial maps is from an experiment done by Stevens and Coupe (3). In the study, students at the University of San Diego in California were asked to estimate the direction of their city from Reno, Nevada. Most students estimated the direction as northeast, when in fact, Reno is northwest of San Diego. The authors hypothesized that the participants' estimates were influenced by the fact that Nevada is basically due east of California. Other studies have found similar results. Studies have shown that North Americans tend to locate European cities south of North America when they are of similar latitudes (4). Thus, it would seem that participants had a general hierarchical cognitive representation of the United States that is generally minimalist, and from this, they generalized their decisions about individual points within the United States.

The robotics community has devoted an inordinate amount of time and computational power to creating exact Euclidian maps of environments, when it is not clear that this is absolutely necessary for efficient navigation through the world. Research from cognitive psychology tells us that general maps of topological relationships are more efficient and robust. There have been 
some recent papers in the robotics community showing promise for solving the SLAM problem without using explicit localization (5). The SLAM problem involves defining locations and possible locations for the robot to navigate to without using a predefined map. We feel that a non-explicit representation for robot localization is the most promising direction for future research.

\section{Method}

For this research, a Pioneer P3-DX robot from ActivMedia Robotics was used. The robot had an on-board computer system running the Linus Torvald's UNIX ${ }^{1}$ version 7.3 operating system. The robot was equipped with the ARIA (Advanced Robotic Interface for Applications) development environment which is a collection of $\mathrm{C}++$ libraries developed by ActivMedia for robotic control. The robot was equipped with SONAR (sound navigation and ranging), a SICK ${ }^{2}$ laser system and a Canon VC-C4 camera. During the early stages of knowledge generation for this study, a real-world area with real obstacles was used. For the second part of the study, when the specific interest was localization, the simulated robot software provided by ActivMedia was used. The ActivMedia simulator software also simulates error associated with robot movement and localization.

\section{Procedure}

For the knowledge development phase, a robotic test bed was developed in order to allow the robot to explore a small world in real time. The test bed included boxes and obstacles which were positioned in a room to allow the robot to navigate in a fairly complex world. This world was also duplicated in the simulated environment for the localization phase.

\subsection{Background}

The SS-RICS was greatly inspired by recent developments in cognitive psychology, especially computational models of cognition, primarily ACT-R (Adaptive Control of Thought - Rational). The SS-RICS is an all-encompassing architecture, (i.e., it includes most major aspects of human cognitive functioning). The architecture includes an ACT-R-like production system, as well as lower structures that mimic human problem-solving behavior. The architecture does not at this time include emotional behavior or metacognitive behavior.

\footnotetext{
${ }^{1}$ UNIX is a registered trademark of Lucent Technologies, Bell Labs Innovations.

${ }^{2}$ Not an acronym
} 
ACT-R is considered a production system architecture. Production system architectures have been used successfully to mimic human behavior (1) and the production system is the basis of ACT-R, as well as other cognitive architectures including Soar (6). A production system uses a deductive reasoning system that uses relatively simple "if-then" type rules to reach conclusions. The SS-RICS uses the production system as a rule-based problem-solving system. For example, if an action is to determine the identity of a scene, a production system with a specific set of localization rules will be loaded into the SS-RICS and used for localization.

ACT-R was developed through a long history of psychological research, especially in the area of human memory. The SS-RICS uses algorithms developed to mimic human memory. In SSRICS, the strength of memory items is a power function and was based on the activation function developed in ACT-R (1) (figure 1). However, within the SS-RICS, a function was added to allow the activation levels to return to zero (RTZ); this is different from the activation equations developed by Anderson and Lebiere (1). By adding an RTZ, this allows the simulation of a refractory period normally exhibited by neurons.

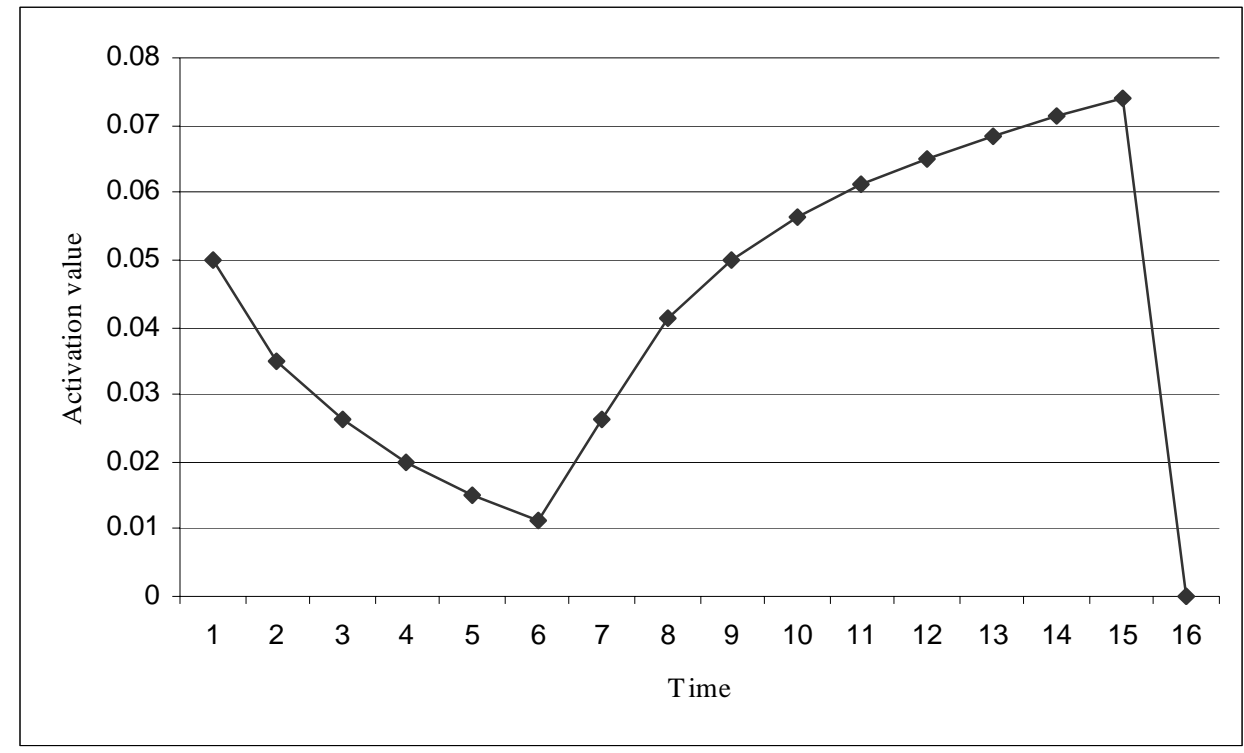

Figure 1. Activation values decreasing, increasing and returning to zero.

\subsection{Knowledge Development}

Our robot was capable of detecting "points" using its SICK laser system. These points are planar points (i.e., points on one continuous plane) that the robot can use to detect the approximate distance to objects in the world. Our first phase of perceptual processing for the robot was called the "neuron level." (Note, while this is called the neuron layer, it is NOT a neural network.) The neuron level uses algorithms to immediately start looking for points in the world which might be grouped together as lines. The overall architecture then attaches an activation value to areas in the robot's SICK laser perception which correspond to areas where possible lines have been detected (figure 2). 
The two graphs in figure 2 showing the robot visual field should be examined together. The top graph shows the robot visual field in degrees and the bottom graph shows the activation value to the corresponding visual field. As shown, activation increases in areas where there is a continuous line representation and decreases in areas where the line representation is not as continuous. This gives the robot a "sense" of where lines are in its SICK laser perceptual field. More importantly, this mimics systems within the human perceptual system at the neuron level by highly activating or strengthening the activity of cells that correspond to important items in the perceptual field.

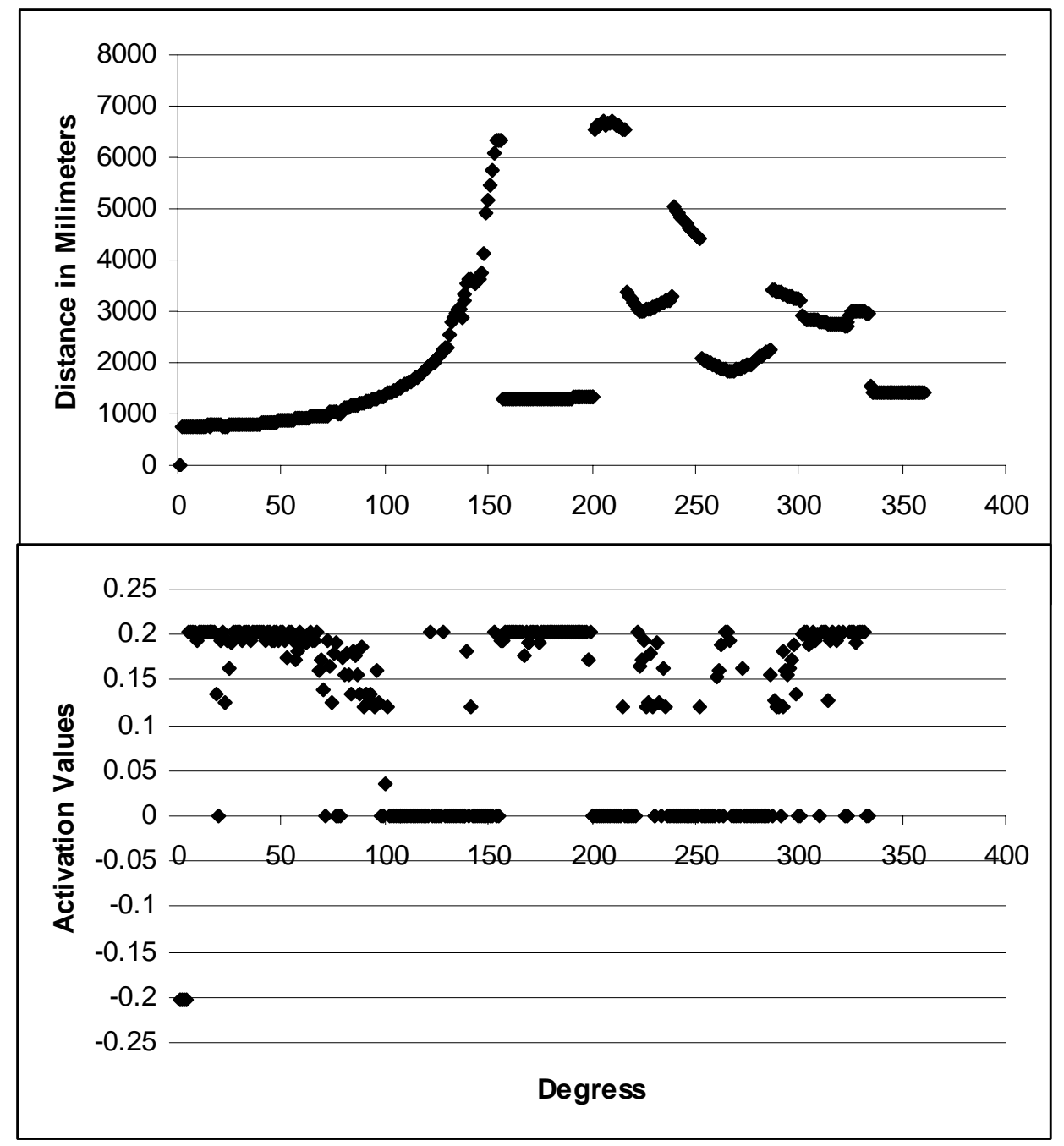

Figure 2. Robotic visual angle in degrees and activation values associated with line objects.

In some ways, the problems of object recognition and the problems of SLAM are intimately tied together. For example, people frequently use object identification as a basis for navigation through the world, (i.e., go to the church, turn left, then go to the large oak tree, and turn right). So, before addressing problems of SLAM, the robot needed a basic understanding of objects in the world before it could determine where in the world it was at any given time. 
In order to allow the robot to navigate through its own environment, the SS-RICS was developed to allow for goal-directed behavior. Cognitive psychologists have shown that much of human behavior is primarily goal directed (7). Goals for human beings can include goals to achieve success, goals to procreate, or goals to satiate hunger. Goals in the SS-RICS architecture may include goals to avoid objects, goals to examine objects, or goals to acquire new information. Goal-directed behavior is not simply the execution of one goal or another but rather a set of conflicting goals that allow complex behavior to emerge from their dynamic interaction. New goals may be added as behavior matures or develops. Conflicting goals also compete for behavioral control, depending on the activation strength of each goal, and internal or external stimuli can change the activation strengths of each goal.

For SS-RICS, goals were developed that were similar to goals that one would expect to see in an intelligent human infant. The main goal was to explore the world; this also included subgoals of avoiding objects and creating memories of the world. Next, the robot gradually developed a goal to ask questions about the world. While the robot was wandering around the room, it periodically asked questions about lines that it had detected. For example, if the robot was interested in a certain line that its neuron layer had identified as important or salient, the robot would ask, "what is this thing at degree -90 to -69?," to which the operator would answer, "it is a line." This was then added to the production system as the symbolic representation (LINE) for what the robot was perceiving at the time it encountered the line. Later in the interaction, the robot may develop another goal to know how the operator knows what constitutes a line or the rules for a line. The user would then enter into the robot what the rules are for a line (lines have end points and start points). This again is added to the production system as rules that constitute a line.

The human-robotic interaction was necessary for the localization behavior, in that it served as a building block for the symbolic representation of the world. Additionally, this interaction simulated how humans learn symbolic rules for objects in the world. It is similar to a child asking "why” over and over. Answers from parents to children's “why” questions frequently include rules. In this case, the robot was motivated by a goal to ask what a line was from its own perceptual experience. It then learned the symbolic representation of a line from its interaction with an operator. It was then able to use the rules that it learned to help determine what objects are in the world, and subsequently, where it was in the world.

\subsection{Localization}

The robot was implemented to develop topological maps that the production system (ACT-R) was capable of loading and analyzing. For example, once the robot was able to identify "lines," it then grouped lines together as scenes. So, in addition to asking questions about objects in the world, the robot gradually developed a goal to store scenes or specific locations of the world. The robot did this by asking "where am I" to which the operator replied "front right of room."

The robot learned five locations of a room that were entered into the ACT-R production system. An approximate layout of the room with each of the five locations is shown in figure 3 . A 
sample set of what was generated for the production system is show in table 1. (Note: the line numbers are arbitrary.)

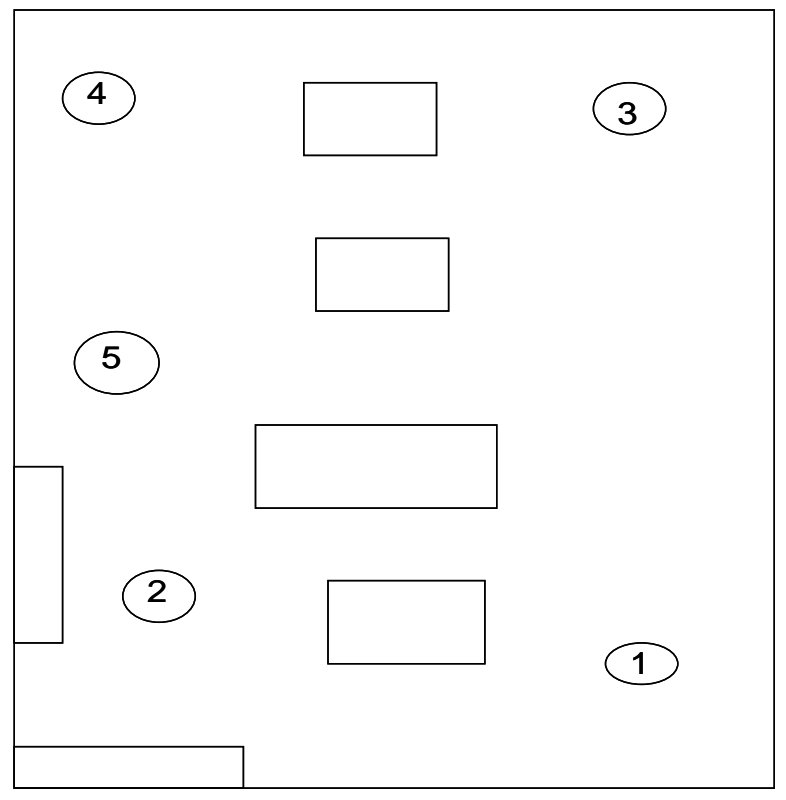

Figure 3. Approximate layout of room and five locations the robot was to learn.

Table 1. Five scene locations, in rule based format, first scan.

\begin{tabular}{|c|c|c|c|c|}
\hline Location 1 & Location 2 & Location 3 & Location 4 & Location 5 \\
\hline $\begin{array}{l}\text { (near-left line5) } \\
\text { (near-right line1) } \\
\text { (near-right line2) } \\
\text { (near-right line3) } \\
\text { (near-right line4) }\end{array}$ & $\begin{array}{l}\text { (far-left line8) } \\
\text { (left line4) } \\
\text { (left line5) } \\
\text { (left line7) } \\
\text { (near line3) } \\
\text { (near-left line6) } \\
\text { (near-right line1) } \\
\text { (near-right line2) }\end{array}$ & $\begin{array}{l}\text { (near line3) } \\
\text { (near-left line4) } \\
\text { (near-left line5) } \\
\text { (near-right line1) } \\
\text { (near-right line2) }\end{array}$ & $\begin{array}{l}\text { center line7) } \\
\text { (left line8) } \\
\text { (near-left line9) } \\
\text { (near-right line2) } \\
\text { (near-right line4) } \\
\text { (near-right line5) } \\
\text { (near-right line6) } \\
\text { (right line1) } \\
\text { (right line3) }\end{array}$ & $\begin{array}{l}\text { center line7) } \\
\text { (left line11) } \\
\text { (near-left line10) } \\
\text { (near-left line8) } \\
\text { (near-left line9) } \\
\text { (near-right line4) } \\
\text { (near-right line5) } \\
\text { (right line1) } \\
\text { (right line2) } \\
\text { (right line3) } \\
\text { (right line6) }\end{array}$ \\
\hline
\end{tabular}

As can be seen from the table 1, the production system included only one type of object, a line. Next, the robot was able to encode the general location of the line (i.e., near, far, left, center or right (which are based on threshold values)). This was the only information about each one of the five locations. Next, the robot was placed into approximately the same locations by a human operator in the robotic simulator. The operator only had a rough map of the general locations as shown in figure 3. This new placement generated a new set of five locations. Those locations are listed in table 2. Once the robot was placed in each location the second time, using the ACT$\mathrm{R}$ production system, the robot was able to identify each of the five locations. So, by using only line information and general information about the location of each line (i.e., near-left) the robot was able to determine its locations for five different scenes. 
Table 2. Five scene locations, rule based format, second scan.

\begin{tabular}{|l|l|l|l|l|}
\hline \multicolumn{1}{|c|}{ Location 1 } & \multicolumn{1}{|c|}{ Location 2 } & \multicolumn{1}{c|}{ Location 3 } & \multicolumn{1}{c|}{ Location 4 } & \multicolumn{1}{c|}{ Location 5 } \\
\hline $\begin{array}{l}\text { (near line6) } \\
\text { (near-left line7) }\end{array}$ & (far-left line11) & (near line3) & (center line5) & (center line6) \\
(near-right line1) & (left line10) & (near-left line4) & (left line6) & (left line11) \\
(near-right line2) & (left line7) & (near-left line5) & (near-left line7) & (near-left line10) \\
(near-left line7) \\
(near-right line3) & (near-left line8) & (near-right line2) & (near-right line2) & (near-left line8) \\
(near-right line4) & (near-left line9) & & (right line1) & (near-left line9) \\
(near-right line5) & (near-right line1) & & & (near-right line2) \\
& (near-right line2) & & & (near-right line3) \\
& (near-right line3) & & & (right line1) \\
& (night line5) & \\
& (near-right line4) & & & \\
\end{tabular}

As can be seen from table 3, because of the inherent error in sensor readings, each scan from the same location is slightly different. The near-left line occasionally switches to a near line and then back to a near-left line.

Table 3. Four scans of location 1.

\begin{tabular}{|l|l|l|l|}
\hline \multicolumn{1}{|c|}{ Scan 1 } & \multicolumn{1}{c|}{ Scan 2 } & \multicolumn{1}{c|}{ Scan 3 } & \multicolumn{1}{c|}{ Scan 4 } \\
\hline (near-left line5) & (near line5) & (near-left line5) & (near line5) \\
\hline (near-right line1) & (near-left line6) & (near-right line1) & (near-left line6) \\
\hline (near-right line2) & (near-right line1) & (near-right line2) & (near-right line1) \\
\hline (near-right line3) & (near-right line2) & (near-right line3) & (near-right line2) \\
\hline (near-right line4) & (near-right line3) & (near-right line4) & (near-right line3) \\
\hline & (near-right line4) & & (near-right line4) \\
\hline & & & \\
\hline
\end{tabular}

By using the activation values within ACT-R, this helped to reduce the effects of the error associated with each scan. First, ACT-R groups the lines of similar types together (i.e., near right), then does a comparison of each scan and does a match with existing scans that it has in its memory. Scans that match existing memories receive higher activation values. The logic here is that the more common a scan is, the more likely the scan reflects reality, since the error scans occur less frequently. As can be seen from figure 4, after three ACT-R cycles of matching three groups of lines, ACT-R has determined that the near-right group is the most stable and matches the best to the previous location scans (note, not all the scans used in the ACT-R analysis are included in table 3). Next, the near-left group is slightly less active, primarily because it occurs less often (only one instance in each group, while the near-right group line instance occurs four times in its group). ACT-R has concluded that since it is less active, it is considered less stable and less a representation of true reality. Finally, the near group (which is actually not a group because it is only one line, but the word "group" here is used for consistency since it is treated the same as the other groups of lines within ACT-R) is the least active. This activation level is because it does not occur at all in scans 1 and 3 and occurs only once in instances 2 and 4 . This instance would be considered an error and would be grounds for ignoring or removal in future calculations of localization within ACT-R. 
Another note about the psychological plausibility of this analysis: With the SS-RICS architecture and by using ACT-R, meaningful representations have been grouped together (line groups). For example, with the scene analysis, the representation starts with points, then progresses to lines, then progresses to groups of lines. (ACT-R allows manipulation of the nearleft group of lines shown in the graph as one memory object, so it can be thought of as a single representation.) This is very similar to human memory and gestalt-type knowledge organization.

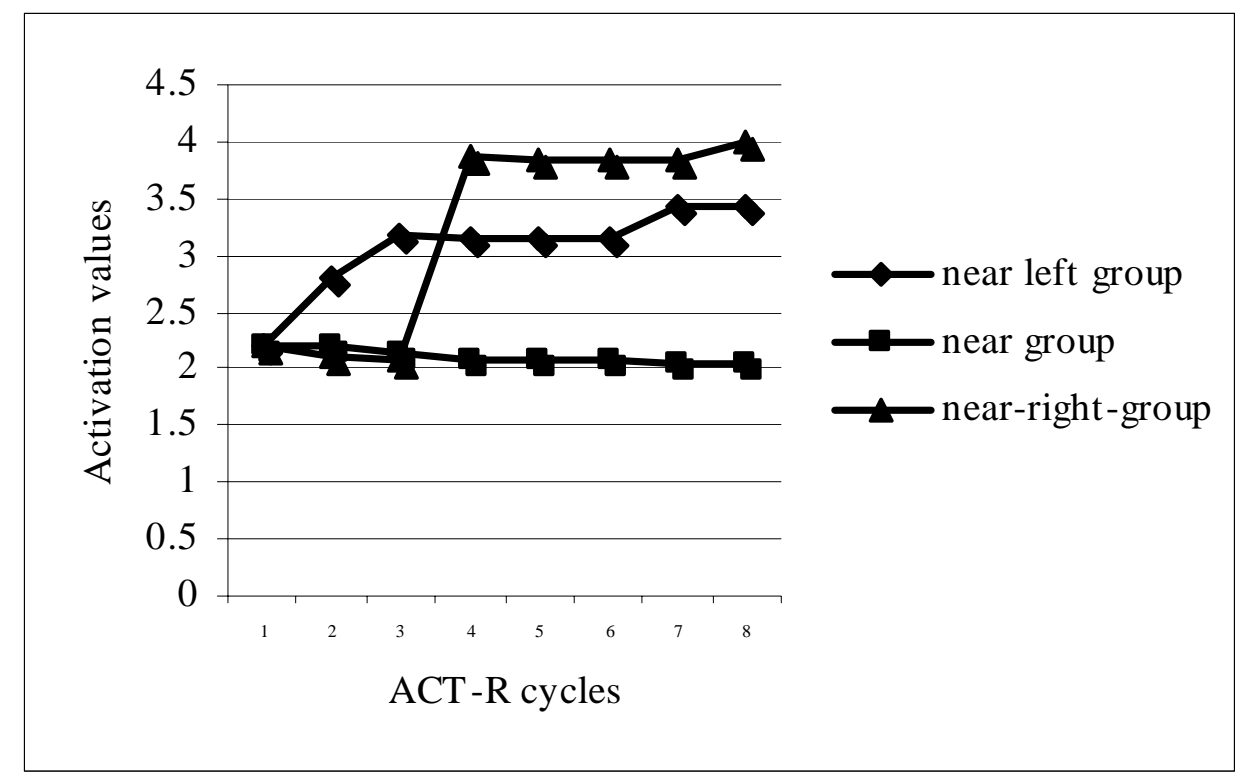

Figure 4. Line group activation values for three groups of lines.

\subsection{Summary}

Using this simple representation, the robot creates general representations of specific locations. By using general representations, we hope that the overall representation is more robust and less prone to failure. Furthermore, this representation should not be affected by increased scaling, which has caused problems for traditional SLAM techniques. The error in this representation does not necessarily increase with the size of the map.

In our study, the five scenes were arbitrary locations on the map. However, ideally, the scenes should be considered "landmarks" or important and salient features of the environment. For example, passing through a doorway, rounding the corner of a hallway, or entering a stairwell would be the kinds of important and salient landmarks that the robot would store in its memory. Ideally, the robot would learn from trial and error navigation that certain salient features of the environment are important for navigation and localization. However, in this case, we have hard coded this information. 
Typically, there should be no need for any representation between the landmarks. The robot only needs to know that it is located at one landmark and perhaps is moving to another landmark. The only representation it might have is that it is "between" landmarks. If an interruption signaled the need to move to a new landmark, then a new landmark could be created at the spot of the interruption which might be between two landmarks. The location of the interruption would create an important event, which would generate the need for a new landmark. However, this would be one of the rare instances when a representation between landmarks would be needed.

\section{Conclusions}

SS-RICS represents the ongoing development of a robotic control architecture that is based heavily on the principles of cognitive psychology. This architecture gave our robot the ability to explore a space in much the same way a human infant would explore a space. By developing a neuron layer similar to the human neuron layer, the robot was attracted to certain salient features of its environment. By examining salient objects and asking the operator questions about salient objects, the robot was then able to develop a symbolic representation of the space and use that representation for localization procedures. The robot was able to correctly identify five similar locations in a simulated environment. The robot was also capable of chunking together representations: first for points, then lines, and then groups of lines and was able to organize groups of lines into a coherent knowledge set. Activation values (developed from human memory decay algorithms) were used to reduce the influence of noise on our localization procedures. Also, note that the robot was able to recognize similar spaces by using a small amount of representations (i.e., lines and locations of lines). It is encouraging to see that just a small amount of representation can go a long way to identifying locations in a space.

Further research will be done to move this simulation into the real world to see if the robot is capable of performing the same tasks in the real world as in the simulation. Additionally, a task will be to give the robot a more detailed representations (edges, corners) and more information about movement (global $\mathrm{X}, \mathrm{Y}$ locations) in order to further improve the topological localization strategies. 


\section{References}

1. Anderson, J. R.; Lebiere, C. The Atomic Components of Thought. Lawrence Erlbaum Associates: Mahwah, NJ, 1998.

2. Kuipers. B. J. The "Map in the Head" Metaphor. Environment and Behavior 1982, 14, 202 220.

3. Stevens, A.; Coupe, P. Distortions in Judged Spatial Relations. Cognitive Psychology 1978, 10, 422-437.

4. Tversky, B. Distortions in Memory for Maps, Cognitive Psychology 1981, 13, 407-433.

5. Choset, H.; Nagatani, K. Topological Simultaneous Localization and Mapping (SLAM): Toward Exact Localization without Explicit Localization. IEEE Transactions on Robotics and Automation April 2001, 17 (2).

6. Newell, A. Soar: A Cognitive Architecture in Perspective, Kluwer Academic. Harvard University Press: Cambridge, MA, 1990.

7. Frese, M.; Sabini, J. (eds) Goal-Directed Behavior. Goal-Directed Behavior: The Concept of Action in Psychology. Erlbaum: Hillsdale, NJ, 1985.

8. Koffka, K. Principles of Gestalt Psychology. Routledge, London, 2001. 
NO. OF

COPIES

ORGANIZATION

1 DEFENSE TECHNICAL

(PDF INFORMATION CTR

ONLY) DTIC OCA

8725 JOHN J KINGMAN RD

STE 0944

FORT BELVOIR VA 22060-6218

1 US ARMY RSRCH DEV \& ENGRG CMD

SYSTEMS OF SYSTEMS

INTEGRATION

AMSRD SS T

6000 6TH ST STE 100

FORT BELVOIR VA 22060-5608

1 INST FOR ADVNCD TCHNLGY

THE UNIV OF TEXAS AT AUSTIN

3925 W BRAKER LN STE 400

AUSTIN TX 78759-5316

1 DIRECTOR

US ARMY RESEARCH LAB

IMNE ALC IMS

2800 POWDER MILL RD

ADELPHI MD 20783-1197

1 DIRECTOR

US ARMY RESEARCH LAB

AMSRD ARL CI OK TL

2800 POWDER MILL RD

ADELPHI MD 20783-1197

2 DIRECTOR

US ARMY RESEARCH LAB

AMSRD ARL CS OK T

2800 POWDER MILL RD

ADELPHI MD 20783-1197

1 ARMY RSCH LABORATORY - HRED

ATTN AMSRD ARL HR M DR M STRUB 6359 WALKER LANE SUITE 100

ALEXANDRIA VA 22310

1 ARMY RSCH LABORATORY - HRED ATTN AMSRD ARL HR MA J MARTIN MYER CENTER RM 2D311

FT MONMOUTH NJ 07703-5630

1 ARMY RSCH LABORATORY - HRED ATTN AMSRD ARL HR MC A DAVISON 320 MANSCEN LOOP STE 166

FT LEONARD WOOD MO 65473-8929
NO. OF

COPIES ORGANIZATION

1 ARMY RSCH LABORATORY - HRED ATTN AMSRD ARL HR MD T COOK BLDG 5400 RM C242

REDSTONE ARSENAL AL 35898-7290

1 COMMANDANT USAADASCH

ATTN ATSA CD

ATTN AMSRD ARL HR ME MS A MARES 5800 CARTER RD

FT BLISS TX 79916-3802

1 ARMY RSCH LABORATORY - HRED

ATTN AMSRD ARL HR MI J MINNINGER BLDG 5400 RM C242

REDSTONE ARSENAL AL 35898-7290

1 ARMY RSCH LABORATORY - HRED ATTN AMSRD ARL HR MM DR V RICE BLDG 4011 RM 217

1750 GREELEY RD

FT SAM HOUSTON TX 78234-5094

1 ARMY RSCH LABORATORY - HRED ATTN AMSRD ARL HR MG R SPINE BUILDING 333

PICATINNY ARSENAL NJ 07806-5000

1 ARL HRED ARMC FLD ELMT ATTN AMSRD ARL HR MH C BURNS BLDG 1467B ROOM 336

THIRD AVENUE FT KNOX KY 40121

1 ARMY RSCH LABORATORY - HRED AVNC FIELD ELEMENT ATTN AMSRD ARL HR MJ D DURBIN BLDG 4506 (DCD) RM 107

FT RUCKER AL 36362-5000

1 ARMY RSCH LABORATORY - HRED ATTN AMSRD ARL HR MK MR J REINHART 10125 KINGMAN RD

FT BELVOIR VA 22060-5828

1 ARMY RSCH LABORATORY - HRED ATTN AMSRD ARL HR MV HQ USAOTC S MIDDLEBROOKS 91012 STATION AVE ROOM 111 FT HOOD TX 76544-5073

1 ARMY RSCH LABORATORY - HRED ATTN AMSRD ARL HR MY M BARNES 2520 HEALY AVE STE 1172 BLDG 51005 FT HUACHUCA AZ 85613-7069 
NO. OF

COPIES

1 ARMY RSCH LABORATORY - HRED

ATTN AMSRD ARL HR MP D UNGVARSKY

BATTLE CMD BATTLE LAB

415 SHERMAN AVE UNIT 3

FT LEAVENWORTH KS 66027-2326

1 ARMY RSCH LABORATORY - HRED

ATTN AMSRD ARL HR MJK J HANSBERGER JFCOM JOINT EXPERIMENTATION J9

JOINT FUTURES LAB

115 LAKEVIEW PARKWAY SUITE B

SUFFOLK VA 23435

1 ARMY RSCH LABORATORY - HRED

ATTN AMSRD ARL HR MQ M R FLETCHER

US ARMY SBCCOM NATICK SOLDIER CTR

AMSRD NSC SS E BLDG 3 RM 341

NATICK MA 01760-5020

1 ARMY RSCH LABORATORY - HRED

ATTN AMSRD ARL HR MY DR J CHEN

12423 RESEARCH PARKWAY

ORLANDO FL 32826

1 ARMY RSCH LABORATORY - HRED

ATTN AMSRD ARL HR MS MR C MANASCO

SIGNAL TOWERS RM 303A

FORT GORDON GA 30905-5233

1 ARMY RSCH LABORATORY - HRED

ATTN AMSRD ARL HR MU M SINGAPORE

6501 E 11 MILE RD MAIL STOP 284

BLDG 200A 2ND FL RM 2104

WARREN MI 48397-5000

1 ARMY RSCH LABORATORY - HRED

ATTN AMSRD ARL HR MF MR C HERNANDEZ

BLDG 3040 RM 220

FORT SILL OK 73503-5600

1 ARMY RSCH LABORATORY - HRED

ATTN AMSRD ARL HR MW E REDDEN

BLDG 4 ROOM 332

FT BENNING GA 31905-5400

1 ARMY RSCH LABORATORY - HRED

ATTN AMSRD ARL HR MN R SPENCER

DCSFDI HF

HQ USASOC BLDG E2929

FORT BRAGG NC 28310-5000

$1 \quad$ ARMY G1

ATTN DAPE MR B KNAPP

300 ARMY PENTAGON ROOM 2C489

WASHINGTON DC 20310-0300
NO. OF

COPIES ORGANIZATION

\section{ABERDEEN PROVING GROUND}

1 DIRECTOR

US ARMY RSCH LABORATORY ATTN AMSRD ARL CI OK (TECH LIB)

BLDG 4600

1 DIRECTOR

US ARMY RSCH LABORATORY

ATTN AMSRD ARL CI OK TP S FOPPIANO

BLDG 459

1 DIRECTOR

US ARMY RSCH LABORATORY

ATTN AMSRD ARL HR MR

F PARAGALLO

BLDG 459

5 DIRECTOR

US ARMY RSCH LABORATORY ATTN AMSRD ARL HR SE T KELLEY BLDG 459 